\title{
SOME ADVANCED WELDING TECHNOLOGIES APPLIED FOR REPAIR WELDING IN POWER PLANTS
}

\author{
Z. Odanović * \\ IMS Institute, Bulevar vojvode Mišića 43, 11000 Belgrade, Serbia
}

Received 31.03.2021

Accepted 03.11.2021

\begin{abstract}
Steels are subjected to many time-dependent degradation mechanisms when they are applied in electric power plants. They are exposed to high temperatures, multi-axial stresses, creep, fatigue, corrosion, and abrasion during such services. Used under these threatening conditions, those materials could develop various damages or failures or even form cracks. Therefore, it is desirable to prevent in-service failures, improve reliability, and extend the plant's operational life. The efficiency of the electric power plant, among other processes, depends on effective maintenance. The paper presents the evaluation of advanced procedures and knowledge in the field of steel repair welding in the maintenance of the power plants. Most repair welding of low alloy steels requires high-temperature post-weld heat treatment (PWHT), but in certain repairs, however, this is not always possible. Application of the nickel-based filler metal could also be an alternative to performing post-weld heat treatment (PWHT). The repair work expenses could be reduced if the repair is performed on-site. The novel developed repair welding procedures presented in this paper were applied for emergency weld repairing of the steel pipelines in thermal power plant, repairing without disassembling the working wheel of the coal mill in thermal power plant and "on-site" repairing turbine shaft of the hydropower plant. For all the presented repair welding procedures, weldability analysis based on the analytical equations and technological "CTS" and "Y" tests to determine the sensitivity to cold and hot crack forming were applied. Tensile tests, absorbed energies tests, banding tests, and hardness measurements were performed on trial joints, which were used to develop and verify the applied methodologies. Presented advanced weld repair technologies enable repairs for a shorter time and at lower costs compared to conventional procedures.
\end{abstract}

Keywords: steel welding; power plants maintenance; emergency repair welding; $\mathrm{Ni}$ based filler material; repair welding on site.

${ }^{*}$ Corresponding author: Z. Odanović, odanovic@ptt.rs 


\section{Introduction}

Systems operating at high temperatures and high pressures in power, petrochemical, and refinery plant are subjected to innumerable degradation mechanisms. However, plant operation can lead to damage and cracking in homogeneous metal materials due to time-dependent processes such as creep, fatigue, oxidation, corrosion, and abrasion. One of the most popular manufacturing processes for joining metals is arc welding, and it is used in structural applications such as pipelines, equipment, and components in thermal and hydro power aggregates. The safety and the economy of the welding process are very important in these structures. Therefore, it is desirable to prevent in-service failures, improve reliability and extend the operational life of the plant. The actual life of homogeneous components of the systems, especially in power plants, will be in excess of the design life, and there are advantages from an economic point of view if the plant life can be safely extended beyond the originally designed life. The efficiency of the power plants, among other processes, depends on effective maintenance [1-8].

Evaluation of advanced procedures and knowledge in the field of repair welding in the maintenance of power plants are presented in the paper. Presented technologies make it possible to carry out repairs in a shorter time and at lower costs compared to conventional procedures. The purpose of the first part of the presented investigation was to estimate replacement of the classical metal arc welding repair procedure with a covered electrode (MMA) with preheating and post weld heat treatment (PWHT) with using a filler metal with similar chemical composition to the parent metal, with repair arc welding technology with filler austenite material based on $\mathrm{Ni}$ and without application of the PWHT, especially in the case of the emergency repair welding. Based on the obtained results procedures presented in this paper, for repair welding of steel pipelines in thermal power plant and some vitally important components of the thermal and hydropower plants facilities were applied. Repair welding of power plant components was performed in one case without disassembling components, and in another case," on site" was performed. The application of these advanced technologies generates significant economic effects. [9-10].

\section{Methodologies}

Most repairs of low alloy steels for elevated temperature applications require high-temperature PWHT. In certain repairs, however, this is not always possible. Specific emergency repair welding procedures can be applied as alternatives to performing PWHT. Application in the case of components breakdown and emergency repair welding on site, special care in defining welding process parameters and selection of filler materials has to be taken.

Over the years, Cr-Mo steels have been applied to produce pipelines and parts as pressure vessels in energetic thermal plants. This type of steel is conditionally weldable and could be successfully welded, and weld repaired if preheating and post weld heat treating procedures are applied [10]. It is usually welded with similar filler material to the parent material. The main purpose of the first part of this study was to compare two repair arc welding technologies for Cr-Mo steels for elevated temperatures applications and define welding procedure for emergency repairing. It is analysed possibilities of replacing this classical weld repairing technology signed as T1 in Figure 1, with advanced, so called "cold welding" technology signed as T2 in the same figure. 


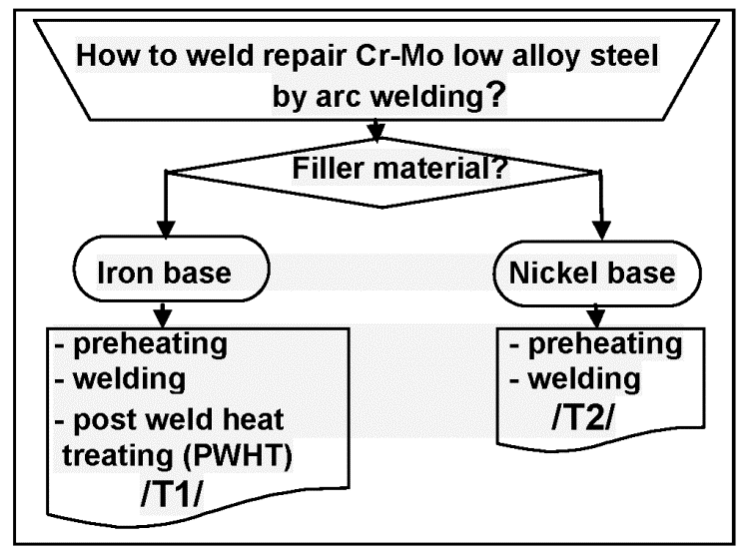

Fig. 1. Selection of possible welding repair procedures for low alloy steel for elevated temperatures applications.

The second technology - T2 with filler austenite material based on Ni without application of the PWHT was performed. Series of trial welds with different welding conditions were realized for both technologies [9-12]. Investigations were performed on low alloy 13CrMo4-5 steel for application at elevated temperatures. Comparison of both repair welding procedures was based on weldability analysis and crack forming sensitivity applying analytical equations and technological "CTS" and "Y" tests. Also, the mechanical properties of both types of trial welded joints were compared.

As a part of the coal fired power stations, a coal milling plant is important, as it supplies a coal and air mixture for combustion in a thermal power plant. The coal milling plant is involved in the wearing process since the raw coal is an abrasive substance. Availability of milling plant is critical to the ability of coal fired power stations to generate electricity, and repair work can be expensive and time-consuming. The second part of this study deal with the application classical weld repair technology T1 with preheating and heat treatment after welding (PWHT), for repairing of an abrasive damaged working wheel of the coal mill in a thermal power plant. As opposed to the usual procedures, repair welding without disassemble of the wheel was performed. The wheel was made of the Cr-Mo steel, cast steel GS 17 CrMo 55. A general view of the working wheel of the coal mill with a signed damaged zone on the disc is presented in Figure 2. The diameter of the wheel was $4100 \mathrm{~mm}$, and the weight was approximately 23 tons. Before weld repairing, as the weldability of this $\mathrm{Cr}-\mathrm{Mo}$ steel is limited, a series of trial welds with different welding and thermal conditions for determining optimal welding conditions were performed. As in the previously presented methodology, weldability analysis employing the analytical equations and using technological "CTS" and "Y" tests and mechanical properties on trial welded joints were applied. 


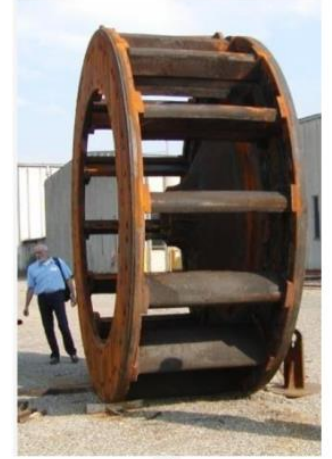

a)

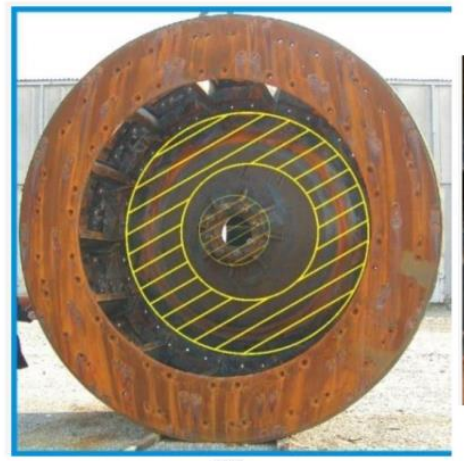

b)

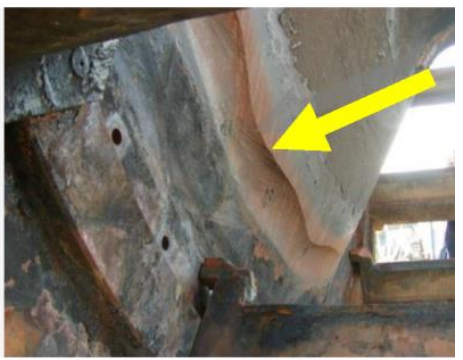

c)

Fig. 2. Working wheel of the coal milling plant: a) side view, $b$ ) damaged zone on the front side of the disc, $c$ ) detail of the damaged zone.

The third part of this study deal with developing repair welding technology of the cracks on the shaft flange of the turbine in the hydropower plant. The hollow steel shaft was $7550 \mathrm{~mm}$ long, with a flange of $2300 \mathrm{~mm}$ in diameter. General view of the hydropower generator and schematic presentation of the hollow shaft of the turbine with locations of detected cracks are presented in Figure 3. The shaft was made of the cast steel 20 GSL ( 20Mn5), and presence damages in the form of cracks were identified on the shaft flange by Non-Destructive Testing (NDT). Since the disassembling of the shaft would be very expensive and considering the amount of damage, it has been decided that repair welding should be carried out on-site without disassembling the shaft. Such a decision called for special researches regarding the determination of the optimum repair welding technology. As the repairing was planned to perform without disassembling of the shaft - on site, application of post weld heat treatment procedures was not feasible. In this circumstance, special care have to be taken in defining repair welding technology, process parameters and selection of filler materials. For the repair welding a welding technology $\mathrm{T} 2$ was selected with $\mathrm{Ni}$ based austenitic covered electrode. A series of trial welds with different welding conditions were performed to develop and verify repair welding technology. As the weldability of this steel is limited, in defining weld repairing parameters, a weldability analysis employing the analytical equations and using technological "CTS" and "Y" tests were performed, and mechanical properties testing of welded joints were carried out on trial joints. 


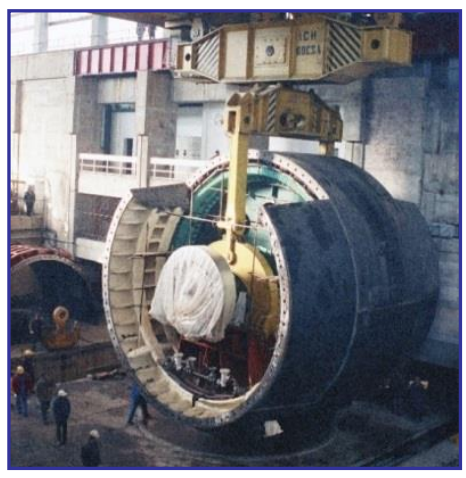

a)

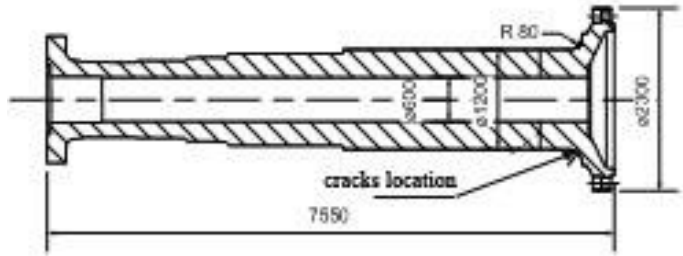

b)

Fig. 3. Hydropower generator a) general view, b) schematic presentation of the hollow shaft of the turbine with location of appearance of the detected cracks.

\section{Experimental}

Within the scope of this research, the following analyses and activities have been performed:

- Visual examination and the non-destructive testing (NDT) of parent materials before repair welding.

- Analysis of the chemical composition of the investigated materials by Optical Emission Spectroscopy (OES) technique.

- Selection of applicable welding procedures and filler materials.

- Weldability analysis of sensitivity to crack forming of the all parent material by the analytical equations and data from analysis of the chemical composition. The following parameters: carbon equivalent $\left(\mathrm{C}_{\mathrm{EKV}}\right)$, crack parameter $\left(\mathrm{P}_{\mathrm{CM}}\right)$, parameter for cold cracks $(\mathrm{Pw})$, parameter for hot cracks susceptibility (HCS), susceptibility of steel to stress relieve $(\Delta \mathrm{G})$ and reheat cracking index (Psr)were calculated [11-15].

- Technological tests as Controlled-Thermal-Severity Test (CTS) and Tekken Test (Y test) for weldability analysis of sensitivity to crack forming of all steels used as parent materials in present investigations were carried out [16-20].

- Mechanical and technological properties testing of the trail welds, as tensile and impact energy testing, bending and hardness testing according to corresponding standards were performed.

- Metallographic investigations as macrostructural and microstructural investigations were conducted using Light Optical Microscopy (LOM).

- According to optimally selected procedures, repair weldings were performed.

- After repair welding, all welded joints by the non-destructive testing methods (NDT) were controlled. 


\section{Results and discussion}

Comparison of the emergency repair welding technology T2 with classical technology $T 1$

In the first part of the study, the trial welds and repair welding were performed for low alloy Cr-Mo steels applied at elevated temperatures as well as for 13CrMo4-5 steel applied in hot-rolled conditions. Welding of the steel by the metal arc welding procedure with the covered electrode (MMA - 111) was applied. For the classic procedure (T1) filler material with similar chemical composition to the parent metal, electrode E CrMo1 R 25 (Castolin 71D) was used. For the procedure with filler material based on Ni (T2), electrode EN ISO 14172: E Ni6182 /NiCr15Fe6Mn/ (Castolin 2222 XuperNucleo Tec) was used. The parent metal's chemical composition and mechanical properties (13CrMo 4-5) are presented in Tables 1 and 2, while the chemistry of the filler material in Tables 3 and 4 are shown. Trial weldings of the steel on test pieces in size of 350x150x10 mm were performed. The joints, as single V butt welds, with $60^{\circ}$ groove were prepared [9-10].

Table 1. Chemical composition of the parent metal (13CrMo4-5) [wt. \%].

\begin{tabular}{|c|c|c|c|c|c|c|c|c|}
\hline & $\mathrm{C}$ & $\mathrm{Si}$ & $\mathrm{Mn}$ & $S$ & $\mathrm{P}$ & $\mathrm{Cr}$ & Mo & $\mathrm{Fe}$ \\
\hline $\begin{array}{l}\mathrm{EN} \\
10028-2\end{array}$ & $0.08-($ & $30.15-$ & 50.4-1.0 & $\begin{array}{l}\max . \\
0.025\end{array}$ & $\begin{array}{l}\max . \\
0.030\end{array}$ & $0.7-1.15$ & $0.40-0.60$ & rest \\
\hline $\begin{array}{l}\text { Measurec } \\
\text { values }\end{array}$ & $d_{0.17}$ & 0.28 & 0.59 & 0.009 & 0.013 & 1.07 & 0.42 & rest \\
\hline
\end{tabular}

Table 2. Mechanical properties of the parent metal (13CrMo 4-5).

\begin{tabular}{|c|c|c|c|c|}
\hline & $\begin{array}{l}\text { Y. S. R } \mathrm{p}_{\mathrm{p} .2} \\
{[\mathrm{MPa}]}\end{array}$ & $\begin{array}{l}\text { T.S. } \mathrm{R}_{\mathrm{m}} \\
{[\mathrm{MPa}]}\end{array}$ & $\begin{array}{l}\text { Elong. } A_{5} \\
{[\%]}\end{array}$ & $\begin{array}{l}\text { Energy } \\
\text { absorbed } \\
\mathrm{C}_{\mathrm{V} 300 / 2}[\mathrm{~J}]\end{array}$ \\
\hline EN 10028-2 & $\min .300$ & $450-600$ & $\min .20$ & $\min .31$ \\
\hline \multicolumn{2}{|c|}{ Measured values436 } & 540 & 35 & 83.5 \\
\hline
\end{tabular}

Table 3. Chemical composition of the filler materials (pure weld metal) [wt. \%].

\begin{tabular}{llllllllll}
\hline Electrode type & Procedure & $\mathrm{C}$ & $\mathrm{Si}$ & $\mathrm{Mn}$ & $\mathrm{Cr}$ & $\mathrm{Mo}$ & $\mathrm{Ni}$ & $\mathrm{Fe}$ & $\mathrm{Nb}$ \\
\hline E CrMo1 R 25 & $\mathrm{T} 1$ & 0.06 & 0.30 & 0.50 & 1.09 & 0.49 & $/$ & rest & \\
Ni base electrode & $\mathrm{T} 2$ & 0.024 & 0.17 & 6.13 & 15.89 & 1.03 & rest & 9.26 & 1.69 \\
\hline
\end{tabular}

Table 4. Mechanical properties of the filler materials.

\begin{tabular}{|c|c|c|c|c|c|c|}
\hline Electrode type & Procedure $_{[\mathrm{MPa}]}^{\text {Y.S. }}$ & $\begin{array}{c}\mathrm{R}_{\mathrm{p} 0,2} \text { T.S. } \mathrm{R}_{\mathrm{m}} \\
{[\mathrm{MPa}]}\end{array}$ & $\begin{array}{l}\text { Elong. } \\
{[\%]}\end{array}$ & $\mathrm{A}_{5}$ & $\begin{array}{l}\text { Energy } \\
\text { absorbed } \\
\mathrm{C}_{\mathrm{V} 300 / 2} \\
{[\mathrm{~J}]}\end{array}$ & HB \\
\hline E CrMo1 R 25 & $\min .490$ & $590-690$ & $\min .20$ & & $\min .55$ & $\sim 310$ \\
\hline Ni base electrode & $\sim 390$ & $620-690$ & $40-45$ & & $\sim 120$ & $180-220$ \\
\hline
\end{tabular}


Weldability analysis of the investigated steel $13 \mathrm{CrMo} 4-5$, based on the analytical equations and steel data from literature has shown following results: carbon equivalent $\left(\mathrm{C}_{\mathrm{EKV}}=0.566\right)$, crack parameter $(\mathrm{PCM}=0.290)$, parameter for cold cracks $(\mathrm{Pw}=$ $0.375)$, parameter for hot cracks susceptibility $(\mathrm{HCS}=1.73)$, susceptibility of steel to stress relieve $(\Delta G=2.16)$ and reheat cracking index $(\mathrm{Psr}=0.09)$. The results for $\mathrm{C}_{\mathrm{EKV}}$; pointed out that steel is conditionally weldable. The PCM, PW and HCS results showed moderate sensitivity to cold and/or hot cracks. Calculated parameters for the sensitivity of steel to stress relieve cracks forming, $\Delta \mathrm{G}$ and Psr; has shown a tendency of the steel to this kind of crack forming. These results were shown that technological tests for the determination of the steel sensitivity to crack forming were necessary to be applied. So, to assess sensitivity to cold and hot and cold cracks formation Y and CTS tests were performed. Welding of technological tests without preheating and PWHT with heat inputs between 0.9 to $1.3 \mathrm{~kJ} / \mathrm{mm}$ was performed. The results of $Y$ test showed that in the welds obtained with conventional filler metal, cracks are evidenced. On the other hand, the Y test welded with nickel base filler metal, there was not shown the appearance of cracks in the welds. Peak hardness in the HAZ of parent metal obtained with both filler metals were on the same level of about 350 HV1. The hardness of the weld metal of the conventional filler metal was about $250 \mathrm{HV} 1$ and it was higher than for Ni based weld metal as the values of about 180 to $200 \mathrm{HV} 1$ were obtained. The CTS testing results for both investigated filler metals did not show the presence of cracks. The appearance of cracks in the case of $\mathrm{Y}$ test with conventional filler metal was indicated, in contrast to the CTS test, where no crack was evidenced, and it could be a result of sharper conditions of the Y weldability test.

The trial welds and repair welding in accordance with the following parameters were performed. For standard weld repairing procedure (T1); after parent metal preheating at 473-483 K, standard multi run metal arc welding procedure with a covered electrode (MMA - 111) was applied. Root pass and first filling pass were obtained by an electrode $(\varnothing 2.5 \mathrm{~mm})$ with similar chemical composition, as presented in Table 3. Each successive pass (3-5) was welded by using a $\varnothing 3.25 \mathrm{~mm}$ electrode, with heat input between 0.9 and $1.6 \mathrm{~kJ} / \mathrm{mm}$. After welding a PWHT was performed at an annealing temperature of $995 \mathrm{~K}$ for $1 \mathrm{~h}$, and plates were subsequently cooled on air. For the procedure with filler material based on $\mathrm{Ni}$ (T2), preheating at 333-353 K was performed. The order of weld passes has followed the sequence in approximately the same way as in the T1 procedure. Welding with a heat input of 0.8 to $1.05 \mathrm{~kJ} / \mathrm{mm}$ was performed. Root pass with Ni-based austenite electrode in diameter of $\varnothing 2.5 \mathrm{~mm}$ was welded, while other passes with the electrode in diameter of $\varnothing 3.25 \mathrm{~mm}$. During welding, after each welding seam was deposited, it was hammered. 


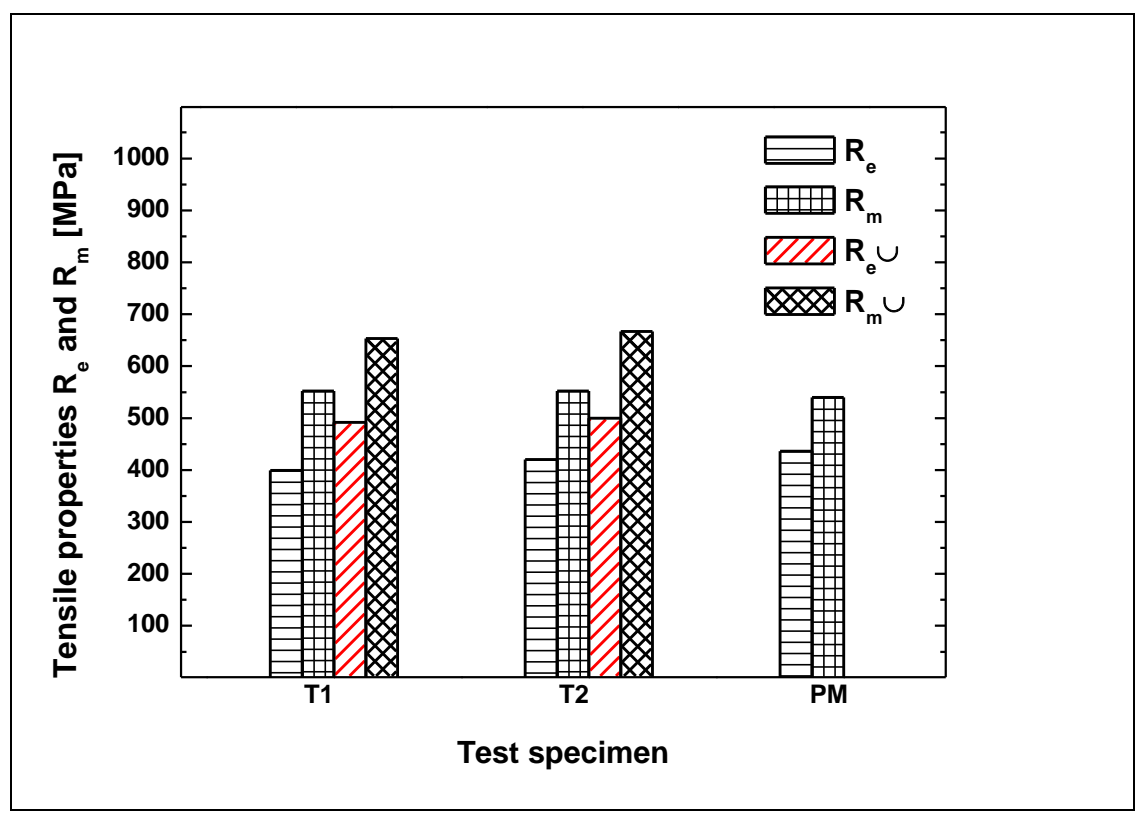

Fig. 4. Tensile testing results for different repair welding technologies, $T 1$ - classical and T2 - with Ni base filler metal and for parent metal PM on samples with parallel sides $(R e, R m)$ and concave sides (Re $\cup, R m \cup)$ for weld metal [9].

After welding of trial plate welds, all the samples were tested by the NDT test, and defects were not identified in the welds. Welded plates were sectioned and machined to standard samples for cross weld tensile testing and impact tests. Tensile testing results of samples with parallel and concave sides in Figure 4 are presented. Obtained tensile properties results of samples obtained by the welding procedure $\mathrm{T} 1$ and T2 with parallel sides are on the same level of $550 \mathrm{MPa}$ for tensile strength and at about 400-420 MPa for yield strength. These values are matched properties of the parent metal. Tensile properties of both investigated welding procedures for samples with concave sides are also on the same level of about $650 \mathrm{MPa}$ [9-11].

Table 5. Impact testing results investigated repair welding procedures and estimated fracture mechanics parameters as stress intensity factor KIc and dynamic stress intensity factor Kid [10-12].

\begin{tabular}{llllll}
\hline $\begin{array}{l}\text { Welding } \\
\text { procedure }\end{array}$ & $\begin{array}{l}\text { Notch } \\
\text { position }\end{array}$ & $\mathrm{C}_{\mathrm{V} 300 / 2,[\mathrm{~J}]}$ & $\begin{array}{l}\mathrm{KIc}, \\
{[\mathrm{MPa} \sqrt{\mathrm{m}}]^{(\mathbf{1})}}\end{array}$ & $\begin{array}{l}\mathrm{KIc} \\
{[\mathrm{MPa} \sqrt{\mathrm{m}}]^{(\mathbf{2})}}\end{array}$ & $\begin{array}{l}\text {,KId, }[\mathrm{MPa} \sqrt{\mathrm{m}}] \\
\text { (2) }\end{array}$ \\
\hline T1 & WM & 81 & 142 & 182 & 104 \\
Conventional & HAZ & 83 & 143 & 184 & 105 \\
T2 & WM & 93 & 155 & 200 & 111 \\
Ni-based & HAZ & 89 & 152 & 193 & 109 \\
PM - Parent & 84 & 150 & 185 & 105 \\
Mat. & & & & & \\
\hline
\end{tabular}

Comment: (1) - Values are estimated based on the measured $\mathrm{CV}_{300 / 2}$ and $\mathrm{Re}$ (2) - Values estimated based on the absorbed energies 
Results of the weld metal hardness are on the same level for both procedures. In the HAZ hardness of the joint welded by the procedure T1 with PWHT are on the level or lower to the weld metal, but higher than the hardness of the parent metal. It is evident a peak in hardness in HAZ for the procedure T2, but maximal values are below 270 HV1. For investigated welding procedures and parent metal results of impact testing in Table 5 are illustrated. From the results, it is evident that absorbed energies are in the range of the parent metal for both procedures $\mathrm{T} 1$ and $\mathrm{T} 2$. To presume the behavior of welded joints in the presence of a crack, some of the parameters of fracture mechanics, according to the equations from the literature, were estimated [9, 12]. For the parent material and for both weld repairing technologies T1 and T2, stress intensity factor KIc and dynamic stress intensity factor KId were estimated. For welded samples, these values for weld metal and heat affected zone were determined. From the results shown in Table 5, it is evident that stress intensity factor KIc and dynamic stress intensity factor KId had slightly higher values for repairing procedure with Ni base electrode (T2) compared to standard weld repairing procedure (T1).

Obtained results have shown that investigated steel 13CrMo4-5 is air hardenable and subjected to cracking if it is not properly handled. It is conditionally weldable steel and could be successfully welded and weld repaired by standard electro arc procedures with the special care, and application of preheating, post weld heat treating, and other precautionary measures. In certain repairs, however, this is not always possible to perform PWHT as in the case of repair welding on-site in the plant. In that cases, as presented results had shown, advanced repair arc welding methods with Ni-based filler metal (T2) could be successfully applied.

Repair welding of the thermal power plant parts without disassembling with applying procedure $T 1$

The second part of the study presents experiments and repair welding of the cast steel GS-17CrMo55. This steel is intended for application at elevated temperatures. Chemical composition and mechanical properties in the Tables 6 and 7 are presented [20-21].

Table 6. Chemical composition of the cast steel GS - 17 CrMo 55.

\begin{tabular}{|c|c|c|c|c|c|c|}
\hline \multicolumn{6}{|c|}{ Chemical composition, [mass. \%] } & \multirow[t]{2}{*}{ Standard } \\
\hline$\overline{\mathrm{SC}}$ & $\mathrm{Si}$ & Mn & $\mathrm{P}$ & $\mathrm{S}$ & Mo & \\
\hline $\begin{array}{l}0.15 \\
0.20 \\
\end{array}$ & $\begin{array}{c}-\max . \\
0.60\end{array}$ & 0.50 & ${ }^{00} \begin{array}{l}\max . \\
0.020\end{array}$ & $\begin{array}{l}\max . \\
0.020\end{array}$ & $1.00-1.500 .45-0.65$ rest & $\begin{array}{l}\text { EN } \\
10213 \\
\end{array}$ \\
\hline
\end{tabular}

Table 7: Mechanical properties of the cast steel GS - 17 CrMo 55.

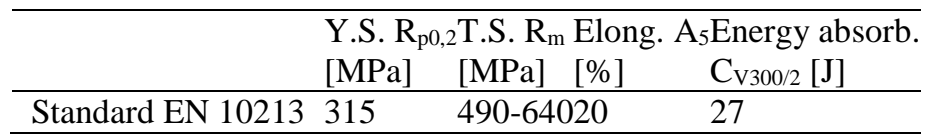

Weldability analysis of the cast steel of the wheel according to methodology and equations summarized in literature was performed [21, 22]. For the investigated steel GS 17 CrMo 55, the following results are obtained for $\mathrm{C}_{\mathrm{EKV}}=0.64-0.67$; which point 
out that steel is conditionally weldable. The results of: $\mathrm{PCM}=0.32 ; \mathrm{Pw}=0.36$ and HCS $=2.6$ are showed moderate sensitivity to cold and/or hot cracks. Calculated parameters for the sensitivity of steel to stress relieve cracks forming $\Delta \mathrm{G}=0.06$ and $\mathrm{Psr}=0.47$; has shown a tendency of the steel to this kind of crack. Results are shown that some technological tests for the determination of the steel sensitivity to crack forming are necessary to be applied. Preheating temperature is also calculated by the analytical equations [21, 22]. Results have shown that recommended temperature is in the interval from $150{ }^{\circ} \mathrm{C}$ to $200{ }^{\circ} \mathrm{C}$. Therefore, in order to assess sensitivity to cold and hot cracks formation $\mathrm{Y}$ test was performed. For investigations, standard electro arc procedures with filler materials similar to parent material were applied. Results have shown that the hardness of the weld metal is slightly higher than the parent material and cold or hot cracks have not occurred. Obtained results have shown that investigated cast steel GS17 CrMo 55 is conditionally weldable and that standard electro arc procedures with preheating and PWHT could be applied with carefully selected filler materials.

Based on the analyzed crack sensitivity of the investigated cast steel and requirements for the repair welding, electro arc processes as manual metal arc welding with covered electrode (MMA - 111) process and flux cored wire metal arc welding with active gas shield (FCAW/AG - 136) process, are selected for the repair welding of the wheel. Requirements for moderate hardness and low content of the hydrogen in weld metal have influenced the selection of the filler metals. Also, an interlayer based on austenitic steel is decided to be used in repair welding. Based on these requirements, filler materials with similar chemical composition to parent material are selected in the form of the electrodes (stick, $\square \varnothing 3.25 \mathrm{~mm}$ and $\square \varnothing 4.00 \mathrm{~mm}$ ), and flux cored wire of $\varnothing 1.2 \mathrm{~mm}$ was used. Heat inputs for weld repairing, trial and control welds (according to standard EN 288), between 0.7 to $1.2 \mathrm{~kJ} / \mathrm{mm}$ were applied as multipass welds. Weddings on $15 \mathrm{~mm}$ thick plates were applied. The chemical composition of the applied filler materials and mechanical properties of pure weld metal are shown in Tables 8 and 9 [20-21].

Table 8. Weld metal chemical composition of the used filler materials in [mass. \%].

\begin{tabular}{|c|c|c|c|c|c|c|c|c|}
\hline Filler material & Form & $\mathrm{C}$ & $\mathrm{Si}$ & Mn & $\mathrm{Cr}$ & Mo & $\mathrm{Ni}$ & $\mathrm{Fe}$ \\
\hline ECrMo1 B42 & Basic coated electrode & 0.08 & 0.45 & 0.80 & 1.10 & 0.50 & / & rest \\
\hline E18 8 Mn B22 & Basic coated electrode & 0.12 & 0.80 & 7.00 & 19.00 & I & 9.00 & rest \\
\hline TCrMo1BC(M)3 & 3Basic flux cored wire & 0.06 & 0.40 & 1.00 & 1.20 & 0.50 & I & rest \\
\hline
\end{tabular}

Table 9. Mechanical properties of the filler materials.

\begin{tabular}{|c|c|c|c|c|}
\hline Filler material & $\begin{array}{l}\text { Y.S. Rl } \\
{[\mathrm{MPa}]}\end{array}$ & $\begin{array}{l}\text { T.S. Rm } \\
{[\mathrm{MPa}]}\end{array}$ & $\begin{array}{l}\text { Elong. A5 } \\
{[\%]}\end{array}$ & $\begin{array}{l}\text { Energy absorb. } \\
\mathrm{CV}_{300 / 2}[\mathrm{~J}]\end{array}$ \\
\hline ECrMo1 B42 & $>470$ & $570-670$ & $>20 \%$ & 95 \\
\hline E18 8 Mn B22 & $>350$ & $590-690$ & $>40 \%$ & 80 \\
\hline TCrMo1BC(M)3 & $>460$ & $550-650$ & $>20 \%$ & 110 \\
\hline
\end{tabular}

Mechanical properties and hardness of the control welds in Tables 10 and 11 are presented. 
Table 10. Tensile properties of the control welds.

\begin{tabular}{lllll}
\hline $\begin{array}{l}\text { Weld } \\
\text { process }\end{array}$ & $\begin{array}{l}\text { YS, } \mathrm{R}_{0.2} \\
{[\mathrm{MPa}]}\end{array}$ & $\begin{array}{l}\text { TS, Rm, } \\
{[\mathrm{MPa}]}\end{array}$ & $\begin{array}{l}\text { Place of } \\
\text { rupture }\end{array}$ & Comment \\
MMA & 390 & 506 & BM & PS \\
MMA & $/$ & 595 & BM & CS \\
FCAW & 429 & 535 & BM & PS \\
FCAW & $/$ & 563 & BM & CS \\
\hline
\end{tabular}

Comment: BM - Base Metal, PS - Parallel Sides of the samples,

CS - Concave Sides of the sample

Table 11. Hardness results of the control welds.

\begin{tabular}{llll}
\hline $\begin{array}{l}\text { Weld } \\
\text { process }\end{array}$ & Weld Metal, & HAZ, & Base Metal, \\
HV10 & HV10 \\
\hline MMA & $237-284$ & $195-242$ & $170-230$ \\
FCAW & $240-282$ & $195-272$ & $200-258$ \\
\hline
\end{tabular}

Based on the results of the previous investigations, preheating at $200-220{ }^{\circ} \mathrm{C}$ was used. Repair welding with parameters identical to control welds were applied. After repair welding post weld heat treatment (PWHT) at $700{ }^{\circ} \mathrm{C} / 4 \mathrm{~h}$ was used. As the repair welding of the investigated working wheel of the coal mill, is performed without disassembling of the wheel's parts, for preheating special heating equipment with six heating modules was applied and were presented in Figure 5. In the same figure, a furnace for PWHT is presented. The furnace for stress relieves was made around the wheel. Careful control of the heating and cooling process was applied during the heat treatment. After PWHT a quality of the repaired welds was controlled by the NDT methods. No defects were observed in NDT quality control.

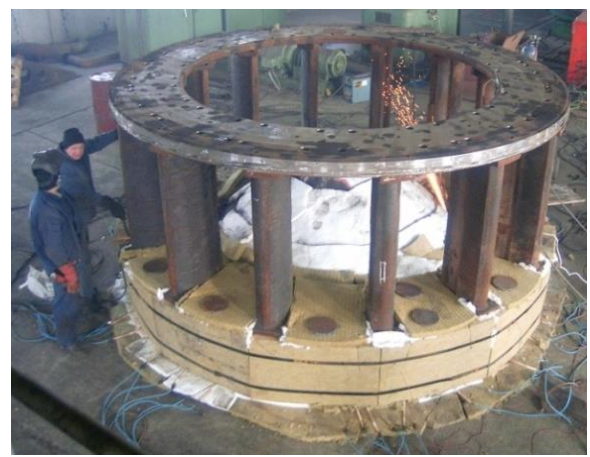

a)

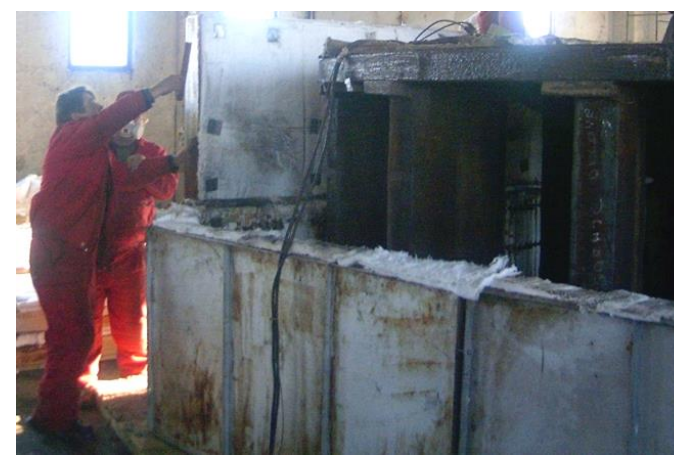

b)

Fig. 5. Equipment for heat treatment during and after repair welding, a) preheating equipment, $b$ ) furnace for PWHT.

Repair welding of an abrasive damaged working wheel of the coal mill in a thermal power plant was performed by standard technology (T1) without dissembling the wheel with significant financial effect as the cost of renovation up to $50 \%$ were reduced. 
Repair welding of the hydroelectric aggregate shaft by the technology(T2) with filler material based on theNi

In the third part of the study, investigations and repair welding on hydropower turbines are presented. The shaft was made of cast steel 20 GSL ( 20Mn5). The main characteristics of this material are high hardenability, sensitivity to the austenitizing temperature and duration of the heat treatment. Results of the parent metal chemical analysis are presented in Table 12, and the results of the tensile testing and impact energy testing are presented in Table 13.

Table 12. Results of the chemical analysis of the parent material.

\begin{tabular}{|c|c|c|c|c|c|c|c|c|c|c|}
\hline \multicolumn{11}{|c|}{ Chemical composition. [mass. \%] } \\
\hline$\overline{\mathrm{C}}$ & $\mathrm{Si}$ & $\mathrm{Mn}$ & S & $\mathrm{P}$ & $\mathrm{Ni}$ & $\mathrm{Cr}$ & Mo & $\mathrm{Al}$ & W & $\mathrm{Fe}$ \\
\hline 0.19 & 0.72 & 1.10 & 0.02 & 0.021 & 0.27 & 0.27 & 0.047 & 0.038 & 0.024 & rest \\
\hline
\end{tabular}

Table 13. Results of tensile and impact energy testing of the parent material.

\begin{tabular}{lllll}
\hline Testing direction & $\begin{array}{l}\text { Y.S. } \mathrm{R}_{\mathrm{p} 0,2} \\
{[\mathrm{MPa}]}\end{array}$ & $\begin{array}{l}\text { T.S. } \mathrm{R}_{\mathrm{m}} \\
{[\mathrm{MPa}]}\end{array}$ & Elong. $\mathrm{A}_{5}[\%]$ & $\begin{array}{l}\text { Energy absorb. } \\
\mathrm{C}_{\mathrm{V} 300 / 2}[\mathrm{~J}]\end{array}$ \\
\hline Transversal & 322 & 560 & 21.6 & 49.4 \\
Longitudinal & 314 & 525 & 15.3 & 58 \\
According toGOST 977-88 & $\min 294$ & $\min 540$ & min 18 & min. 23 \\
\hline
\end{tabular}

Assessing weldability of the parent material steel 20 GSL ( 20Mn5) was performed through the application of analytical expressions for the assessment of resistance to cold cracking, proneness to hot cracking and cracking due to annealing [11, 13-19]. Carbon equivalent applying formulas from the literature is obtained [1315]. The following results were obtained for $C_{E K V}=0.45$; which point that steel was conditionally weldable and preheating and annealing were required. The results of PCM $=0.29$ and $\mathrm{HCS}=2.15$ were showed that steel was prone to the formation of cold and hot cracks and the carbon equivalent level, which indicated the possibility of the creation of brittle phases. That means that, apart from the mechanical and structural characterization of test samples welded to determine the welding technology, it was necessary to carry out technological weldability tests. Preheating temperature is calculated through the use methods presented in the literature [11], based on the chemical composition of the steel. Obtained preheating temperatures were ranged from 150 to $200{ }^{\circ} \mathrm{C}$. Sensitivitytechnological tests such as" CTS" and" Y" on test joints obtained by arc welding of parent material with investigated $\mathrm{Ni}$-based filler material were performed. Based on the results obtained, it could be concluded that this test is highly sensitive to the formation of cold and hot cracks but cracks was not detected.

Results suggested that Ni-based electrode was suitable for repair welding on site by the arc welding process. Considering structural and mechanical properties of the parent material and assumed quality requirements, geometric shape of the shaft flange, construction solution, technological possibilities conditioned by possible on-site repair welding and availability of repair welding equipment, metal arc welding process (MMA - 111) with covered Ni-based electrode without PWHT (repair welding procedure T2) was selected. The chemical composition of the Ni-based filler material was already 
presented in Table 3, while in Table 4, the mechanical properties of the weld metal were presented.

To verify suggested repair technology, testing of mechanical and structural properties was performed on the trial butt joints, which were welded with the investigated filler material. Butt joints using Ni-based electrode in diameter of $\varnothing 3.00$ $\mathrm{mm}$ for root pass and $\varnothing 4.00 \mathrm{~mm}$ in diameter for filling layers were welded. The thickness of the sample plates was $15 \mathrm{~mm}$. For welding, a $60^{\circ} \mathrm{V}$ groove was machined, and $2 \mathrm{~mm}$ in distance between plates was used. Welding in nine passes with electrodes of $3.00 \mathrm{~mm}$ and $4.00 \mathrm{~mm}$ in diameter was performed. Heat input for the electrode in diameter of $3.00 \mathrm{~mm}$ was $9.7-9.9 \mathrm{KJ} / \mathrm{cm}$ and $12.2-12.9 \mathrm{KJ} / \mathrm{cm}$ for the diameter of $4.00 \mathrm{~mm}$. After every pass, peening of the weld metal by the pneumatic hammer was performed [22].

Investigation of mechanical and technological properties of trial welds following the standard EN 288 was performed. Testing results showed that the tensile strength value, determined on specimens with parallel sides, is approximately $510 \mathrm{MPa}$. Values of impact energy for samples taken from weld metal $\left(\mathrm{CV}_{300 / 2}\right)$ were very high and exceeded $120 \mathrm{~J}$. Mean values of impact energy for samples taken from the heat-affected zone ranged from 85 to $125 \mathrm{~J}$ and well exceeded values obtained for the base material, which range from 50 to $60 \mathrm{~J}$, probably because the notch was located in the narrow heat-affected zone, which resulted in spreading of the heat-affected zone on account of the weld metal, thus higher values were obtained. Hardness values for butt welded joints in the heat-affected zone between 220 to 290 HV5 were ranged, while the weld metal hardness from 190 to 220 HV5 was ranged. Macro inspection showed that there were no cracks on all inspected samples [22-25].

Generally, it was decided, based on the previously presented results of the investigations, to repair turbine shaft" on site", without disassembling, but with a number of precautionary measures and strict compliance to the technological discipline.

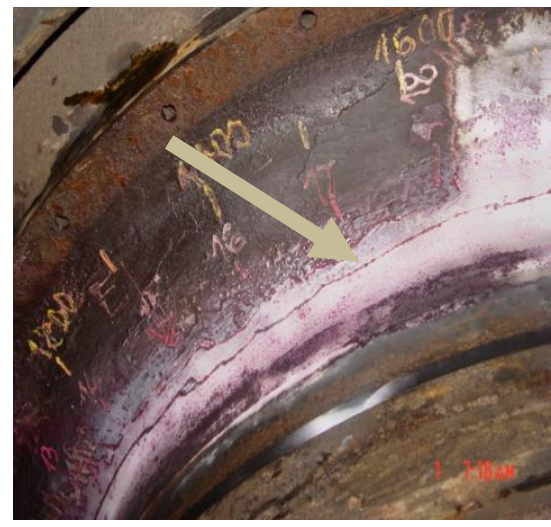

a)

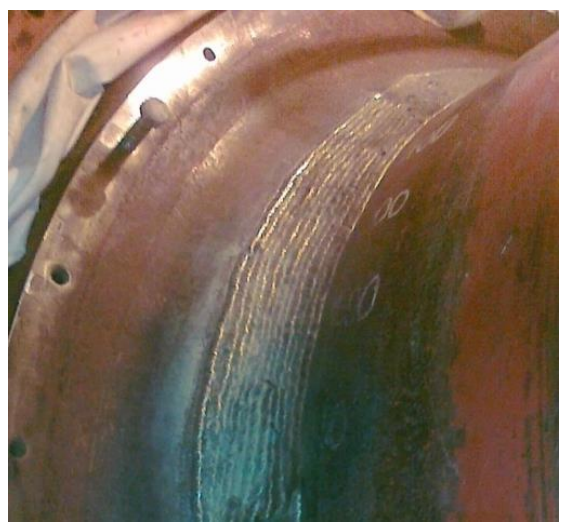

b)

Fig. 6. View of the hydro turbine shaft flange a) appearance of detected crack, b) weld repaired shaft flange. 
General view of the appearance of detected cracks on hydro turbine shaft flange and weld repaired shaft flange in Figure 6 are presented.

Visual interpass inspection and final NDT inspection regarding the state and quality of the repaired zone were performed. Repair welding was done" on site" without disassembling the shaft, and the price was 20 times slower than the production of a new shaft.

\section{Conclusions}

Evaluation of advanced technologies and knowledge in the field of repair welding in the maintenance of thermal and hydro powerplants are presented. Based on the investigation results, the following can be concluded.

Two repair welding procedures applicable for emergency welding on site, were analyzed and compared. Investigations were performed on low alloy pipeline steel 13CrMo4-5 for elevated temperatures applications. It is shown that repair welding procedure, with Ni-base filler material and without PWHT, provided joint properties at the same level to classical repair welding procedure, but with lower expenses.

The repair welding technology based on the classical arc weld repair technology with preheating and PWHT, without disassembling of an abrasive damaged working wheel of the coal mill in milling plant of the coal fired power stations is presented. Optimal welding parameters and filler materials were selected in investigations. Also, optimal heat treatments conditions before, during, and after repair welding were chosen. Application of the presented repairing procedure enables increasing the plant's energy efficiency by decreasing the renovation time, and expenses are reduced up to $50 \%$.

Novel repair welding procedure based on arc welding process with Ni-base covered electrode and without PWHT, applied for reparation of the turbine shaft flange in hydropower plant was also presented in the study. In repair welding procedure development, evaluation of metallurgical weldability of the parent flange metal through testing of mechanical and technological properties and applying "CTS" and" Y" weldability tests were applied. For welding procedure verification, a series of trial welded joints with properties testing were realized. Based on the investigation results, repair welding of the turbine shaft flange, without shaft disassembling, was successfully performed on site. In comparison with the production price of a new shaft, the application of this advanced repair technology is up to 20 times lower. The energy efficiency of the power aggregate is also increased by decreasing the renovation time.

\section{Acknowledgment}

This paper is dedicated to the memory of professor Lubomir Nedeljković.

\section{References}

[1] T. Lant, D.L. Robinson: Int Journal of Pressure and Piping, 78 (2001) 813-818

[2] B. Messer, C. Patrick, S. Seitz: Int Journal of Pressure and Piping, 53 (2006) 365-372.

[3] J. MacIntyre, D. Stansfield, P. Allot, M. Harris: Power Station Maintenance Profitability Through Reliability, First IEE/IMechE International Conference (Conf. Publ. No. 452) ISBN: 0-85296-699-7, (1998) 84-89.

[4] A. Klenk, S. Issler, I. A. Shibli, J. A. Williams: Weld Repair for Creep Applications, OMMI, 2 (2003) 1-32. 
http://www.metserve.co.za/pdf/creep\%2520-\%2520iwshibli.pdf

[5] E. Budzakova, D. Dune, M. Law: Materials Forum, 27 (2004) 45-53.

[6] V. Silva, C. de Albuquerque: Journal of Materials Engineering and Performance, 18 (3) (2009) 324-331.

[7] T. Lant, D.L. Robinson, B. Spafford: Int Journal of Press Vess and Piping, 78 (2001) 813-818.

[8] D. Gandy: The Grades 11 and 12 Low Alloy Steel Handbook, Electric Power Research Institute, Palo Alto, California USA, (2007), 7.6-7.19.

[9] Z. Odanović, M. Arsić, V. Grabulov, M. Djurdjević: Advanced Materials Research, 814 (2013) 25- 34

[10] Z. Odanović, M. Djurdjević, M. Arsić, V. Grabulov, B. Katavić, B. Gligorijević: 2nd IIW European-South American School of Welding and Correlated Processes, Sattledt, Austria, (2012) Document SG-RES-0193-12.

[11] B. Katavić, B. Jegdić, Z. Odanović, N. Hut: Welding and welded structures, 54 (2009)149-155.

[12] B. Katavić, B. Jegdić, Z. Odanović, N. Hut: Welding and welded structures, 55 (2010) 91-96.

[13] Y. Ito and K. Bessyo: IIW-Doc IX-631-69 (1969) 1-18.

[14] N. Yurioka et. al.: Australian Weld Res Ass Melbourne Paper, 10 (1981) 1-18.

[15] I. Hrivnjak: Theory of Weldability of Metals and Alloys, Elsevier Science Publishers, ISBN 0-444-98707-X, Amsterdam (1991) 75-92.

[16] D. Uwerand, H. Höhne: IIW-Doc. IX-1630-91 (1991) 1-15.

[17] N. Yurioka et. al.: Australian Weld. Res. Ass. Melbourne, Paper 10 (1981) 1-18.

[18] EN ISO 17642-2: Destructive test on welds in metallic materials - Cold cracking test for weldments (CTS) (2005).

[19] K. Wilken: Le Soudage dans le Monde, 28 (1990) 127-143.

[20] V. Grabulov, Z. Odanović, B. Katavić, S. Momčilović,B. Tasić: Welding and welded structures 53 (2008) 147-157.

[21] Z. Odanović, V. Grabulov, S. Momčilović, B. Tasić, M. Đurđević, M. Arsić: Welding in the World, 52 (2008) 347-353.

[22] Z. Odanović, V. Grabulov, M. Arsić, R. Miković, R. Mitrović: International Congress on Advances in Welding Science and Technology for Construction, Energy and Transportation Systems (AWST - 2011) (ISBN 978-605-4424-23-8), (2011) 243-248.

[23] Z. Odanovic et al: Welding and welded structures, 56 (2011) 149-166.

[24] Z. Odanović, V. Grabulov, M. Arsić, M. Đurđević, B. Katavić: Proceedings of the IIW International Conference on Global Trends in Joining, Cutting and Surfacing Technology - IIW 2011, (ISBN 978-81-8487-152-4), (2011) 343-350.

[25] D. Momčilović, Z. Odanović: Advanced Materials Research, 1153 (2019) 36-45.

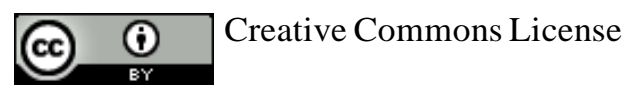

This work is licensed under a Creative Commons Attribution 4.0 International License. 